Clements, C. \& Neal, T.M.S. (in press). Research in criminal psychology. In R.D. Morgan (Ed.) The SAGE Encyclopedia of Criminal Psychology. Thousand Oaks, CA: SAGE.

This is a pre-print version of the chapter that will be available as one chapter in the book referenced above.

This copy may not exactly replicate final version published in the book. It is not the copy of record. The final version of record will be available for purchase from SAGE. See their website for more information: https://us.sagepub.com/en-us/nam

(C) 2017 SAGE Publications. 


\section{Research in Criminal Psychology}

\section{By Carl B. Clements \& Tess M.S. Neal}

"Criminal psychology" is a broad field that overlaps with several subareas of psychology, including correctional (applications to prison settings) and forensic (applications in courtroom settings) psychology. A widely used umbrella term, "psychology-law," also reflects the interdisciplinary commitment of researchers in criminal psychology, who draw from many traditional domains of psychology, including clinical (e.g., assessment, treatment), social (how people and contexts influence us), cognitive (how we think and make decisions), developmental (how we grow and change), and neuropsychology (the biological basis of behavior). This chapter - covering research in criminal psychology - emphasizes the shared reliance on scientific methods characteristic of modern psychology.

Beginning students are often surprised that the field is so heavily grounded in science, both in its strategies of seeking and verifying "facts" and in its breadth of subject matter. Psychology is not, as some skeptics have surmised, merely "common sense." The abundance of counterintuitive research findings and countless unanticipated breakthroughs in understanding complex behavior attest to the unique value of contemporary psychology. Likewise, the field of criminal psychology has moved away from its pre-scientific roots that often mirrored popular declarations about crime and criminals. The field has strived to replace superstitions with empirically-derived insights about why some people break the law, act violently, and are undeterred by the threat of punishment.

To advance our understanding, science must regularly challenge speculation and “common sense" and use research findings to inform practice. For example, in assessing offenders at multiple points of the justice process (arrest, trial, sentencing, placement, treatment 
planning, prediction of risk, etc.), up-to-date tools are increasingly designed to answer specific psycho-legal questions - rather than offering broad statements and using tests never intended to address the issue. Such instruments also are expected to meet a high threshold of reliability and validity, thereby minimizing subjectivity and raising confidence in their accuracy and fairness. The field has also done much to rebut the widely held perception that offenders comprise a unitary cluster. Current evidence reveals multiple pathways to criminal behavior, pathways that imply different prognoses and individualized targets of intervention. Similarly, both legal sanctions and the provision of specific behavior change programs have been increasingly subjected to outcomes evaluations, including cost-benefit analyses.

Many entries in this encyclopedia address some of the above referenced ideas in greater detail. Our goal in this chapter is to introduce the current state of research in criminal psychology, sample the major research methods in the field, stress the importance of evidencebased approaches, and outline several areas of future research.

\section{Why Some People Become Criminals and Others Don't}

Law-breaking is not a rare event, and the range of crimes as defined by legal codes is vast. Strategies adopted to deter or reduce crime necessarily draw from assumptions about "why?" Who are these persons, and how does society respond? One set of answers has resulted in a far-reaching network of prisons created to isolate people from society, primarily for the purposes of rehabilitation and/or punishment. The rationale for this type of closed environment was heavily promoted by early psychological theory, and supported by theological stances and basic legal principles — namely, that individuals freely choose to engage in prohibited behavior and are thus responsible for their actions and the ensuing consequences. Although most 
clinicians and researchers historically have had some faith in the capacity of offenders to change, the choice of methods to promote that change has been controversial for nearly two centuries.

In contrast to legal and theological perspectives for understanding and responding to crime, psychology has moved toward a notably analytic stance and concerned itself with broader questions of causation, intervention, prevention, and evaluation. Because the field has evolved as a behavioral, social, and biological science, psychologists are inclined to apply an objective and multifocal lens to matters of crime and punishment. For example, research in criminal psychology has shown that the exclusive focus on individual, person-centered factors does a poor job of explaining criminal conduct or predicting future criminal behavior. We have learned through thousands of psychological studies that social and environmental contexts also are critically important.

The power of context can overwhelm personal traits or become triggering events that interact with individual predispositions. A clear example of the former was demonstrated in the Stanford Prison Experiment in which randomly assigned student "guards" began to engage in abusive behavior toward their fellow student "inmates." Likewise, the potential negative outcomes predicted by certain youthful traits can be substantially accelerated if the youth faces a violent home life which, in turn, increases the likelihood of aggressive behavior. Context is not limited to one-time events (triggers) but rather can be cumulative over time. The more one smokes, the greater the risk of contracting lung cancer; continued exposure to violence has a parallel negative risk effect. Thus, both individual factors and environmental context must be cataloged in the list of risk factors. Which of these exerts the most power at any given time has become a central question in criminal psychological research. 
Although psychology and other clinical sciences originally followed a medical model with a focus on singular "causes," a more useful perspective has been the above-noted identification and weighting of multiple "risk factors," factors that increase the probability of a given behavior or outcome. Not all smokers become cancerous, but smoking certainly increases one's chances. Adopting a public health model - combining risk and protective factors - has proven quite valuable in understanding, predicting, and designing interventions for preventing and reducing criminal behavior.

Some of the best statistical predictors of who becomes a criminal and who does not include the social and environmental contexts into which people are born, grow, develop and confront on a daily basis. Ethnicity, poverty, and other forms of social and economic disadvantage have a cumulative effect on "risk" for crime and incarceration. Studies have found a strong link between social and economic inequality and violence, as well as between social rejection, aggression, and impaired thinking abilities. We also know from several studies that head injuries are related to aggression, impaired thinking abilities, and imprisonment - and that people from disadvantaged settings are more likely to sustain head injuries throughout their lifetimes. This collection of findings is a good example of how individual and context risk factors interact to influence criminal activity.

Another substantial body of research in criminal psychology has consistently revealed eight risk factors that increase the likelihood of criminal behavior. The identification of these factors is drawn from scores of studies that assessed dozens of offender characteristics and those of their families, associates, community environments, and the like. Four factors are especially robust predictors: a history of criminal behavior, procriminal attitudes (thoughts, values, and beliefs that support criminal behavior), procriminal associates (one's circle of associates who 
espouse procriminal attitudes), and antisocial personality (lack of self-control, pleasure-seeking behaviors, disregard for others). Further evidence of the validity of the "big four" is provided by treatment outcome studies. When these factors are successfully targeted, delinquents and adult offenders are much less likely to reoffend than if these factors are not addressed. The additional components of the "big eight" are: lack of prosocial achievement (employment, education), family or marital discord, substance abuse, and lack of prosocial hobbies or leisure activities. As will be noted later in this chapter, the targeting of dynamic (changeable) risk factors, primarily through social-cognitive-behavioral therapies, promotes more positive outcomes than many historically popular, but often counterproductive approaches.

An important note is that many of the relationships identified in broad studies are correlational and thus do not establish direct causation. For example, despite the positive relation found between poverty and crime, or between lack of educational achievement and crime, we cannot conclude that being poor or dropping out of school directly causes crime. Exceptions to these links are certainly plentiful. Moreover, other variables may actually better explain a given relationship. For example, there is a positive relation between ice cream consumption and death by drowning, a puzzling connection at best. It is hard to imagine that eating ice cream causes people to drown. Rather, a "third variable," namely, summertime, is the more logical common underlying factor. In the case of poverty and crime, underlying "third variables" might include the social rejection, tumultuous community environments, or procriminal associates. The search for causal silver bullets is rarely satisfying. Examining the joint influence of individual traits, abilities, and temperament combined with family, social, and community contexts of people's lives provides a better understanding of a person's likelihood of becoming a criminal and of re-offending. And as we have suggested, the goal of preventing and 
reducing crime is better served through both addressing personal traits and altering negative contexts.

The validity of this interactionist perspective could be challenged if research were to reveal powerful individual traits that seem to override context or, alternatively, to identify engulfing environments that overwhelm personal traits. An example of the former is the apparently treatment-resistant personality of the psychopath. The public often imagines that psychopathic personality is at the base of most crime. Indeed one hallmark of psychopathy is antisocial behavior. People with psychopathic personalities (whether incarcerated or not) generally have an inability to feel empathy for others, show callous emotional responses to situations that bother others, are impulsive and reckless, and are superficially charming and manipulative. Although psychopaths comprise only about $15 \%$ of the criminal population, they may account for a much higher proportion of crimes and are also notably poor candidates for even the most well-researched, evidence-based treatments. However, those who can avoid violence and other criminal acts, and who have sufficient intellectual resources, may well rise to the highest ranks of employment in fields where their lack of prosocial emotions gives them a competitive advantage.

\section{Research Methods in Criminal Psychological Science}

How have we achieved some of these insights? Studying criminals is not easy or straightforward. With good reason, offenders are protected by layers of rules; researchers must apply ethical standards including human subjects' safeguards. These rules evolved, in part, because of historical abuses in which prisoners were used as "guinea pigs." A grossly inhumane example is the experimentation by Nazi doctors who forcibly tested the human body's response to various chemicals. A less obvious example, in the context of an impoverished prison setting, is 
drug testing. In such studies, enrolled offenders neither had a truly free choice - the token pay offered by pharmaceutical companies stood in stark contrast to inmates' lack of funds—nor were they fully informed about the potential risks of experimental medications. Contemporary rules about how researchers are allowed to work with human subjects also come directly from studies in criminal psychology - a well-known example is the Stanford Prison Experiment referred to in the previous section.

The Stanford Prison Experiment was conducted in the early 1970s by social psychologists who wanted to better understand the behavior of prisoners and guards, particularly in relation to each other. The researchers randomly assigned healthy Stanford undergraduates to be either a guard or a prisoner, and placed them together in a converted campus basement “prison." The participants' behaviors became so extreme that the study was cancelled well short of its planned duration. "Guards" began abusing "inmates," and inmates began rioting and experiencing mental health problems. The researchers observed additional harmful outcomes to participants who had been allowed to go "off script." Although the students were subsequently de-briefed and counselled, it was apparent that the experience would not be easily forgotten. This historic experiment served both as an emblem of the powerful impact of prison environments and as a stark warning to researchers to anticipate and prevent harm to their participants. Today’s ethical standards about how we are allowed to study humans owe much to the growing awareness and correction of past abuses.

\section{Decisions Researchers Make about Research Methods}

For all research, the unit of analysis must be determined. Studies in criminal psychology are no different. Some research questions focus at the level of individual persons (e.g., assessing which types of offenders are more likely to be violent), or they may take a broader focus, at the 
level of a system (e.g., comparing the violence rates in different types of prisons). Often, a study will include multiple levels of analysis to provide a view of interacting factors. For example, we might examine whether a cognitive therapy program has different effects on intellectually limited inmates vs. those who have average or above abilities.

Another decision facing researchers is the choice of study design. For example, researchers interested in how children of prisoners are affected by their parent's incarceration could approach this question in different ways. They could survey a sample of prisoners' families at a given point in time, e.g., by mailing out questionnaires or conducting interviews and then analyzing the results. This "snapshot" is relevant to that particular point in time, but could not assess changes over time. To address the question of how children's experiences of their parents' imprisonment may change (e.g., does it get progressively worse? Do children adjust? Are there factors that reduce or amplify negative impact?), the research design requires that data be collected and analyzed across time. Because the answers to these questions may well have implications for public policy, careful attention to design and measurement is critical. Whether addressing basic or complex questions, researchers in criminal psychology need to have a solid understanding of research methods.

\section{The Progressive Movement to Evidence-Based Approaches}

The kinds of studies cited in this chapter provide a growing base for decision making. Research in many fields of psychology, including criminal psychology, has as a goal not only the understanding of behavior but also the application of findings to human well-being and sensible public policy. Especially in the criminal justice system, public policy has often reflected widespread social attitudes and popular opinions rather than evidence-based findings. For example, the "get tough" movement of the last third of the $20^{\text {th }}$ Century, emphasizing harsh 
punishment, has had a series of unintended consequences including economic black-holes, overreliance on incarceration, and worsening offender outcomes. A good example is boot camp programs, where juveniles who were sent to military-style settings actually learned tricks of the trade and reoffended at higher rates than youths who didn't attend these types of programs. The value of research in this context is to examine the actual outcomes in comparison to the hopedfor results. "We think this ought to work" is no substitute for research that helps identify "what works."

Interestingly, the retreat from the mid-century goals of rehabilitation was itself fueled by "studies" that collectively showed no difference in recidivism rates between "treated" and "untreated" prisoners. Although the "get tough" trend has persisted for three decades, subsequent re-analysis revealed two critical research flaws: First, the studies compared offender groups of unknown equivalence, and thus the validities of results were likewise unknowable. Appropriate control groups, admittedly hard to engineer in justice settings, are the gold standard in treatment outcomes research. Second, many early so-called rehabilitative interventions were, by today's standards, quite weak. In addition, treatment providers or supervisors often failed to monitor whether treatments were actually delivered as intended. Thus, many of the studies underlying the "rehabilitation doesn't work" conclusion failed to provide trustworthy results. Bad science may have supported bad policy.

From these flaws, researchers now recognize how critical it is to closely monitor treatments in terms of their duration, intensity, client attendance, engagement, and expertise of the interventionists. Consider a cooking parallel: the latest cake recipe in your favorite magazine is touted to be a good one. As a beginner, you try it out, and the result is mediocre at best. Do you discard the recipe? Perhaps, but only if you can document that your instructional guide (the 
recipe) was printed correctly, that you followed all the sequential steps, cooked it long enough and at the stated temperature, in a reliable oven, while also accounting for your status as a kitchen beginner. The plausible alternatives to the "bad recipe" verdict are manifold.

The lessons of this example demonstrate the need for rigorous requirements if studies are to be used as a basis of policy recommendations. The standards include the requirement that comparison groups (Treatment X vs. Treatment $\mathrm{Y}$ ) must be as equivalent as possible on all important measures (e.g., age, crime history, learning capacity) so that any differences in outcomes are likely to be the result of intervention and not characteristics of the offenders. Alternatively, it would be important to know if Treatment X might prove beneficial to certain sub-groups but not others. Such studies have provided clear evidence, for example, that "high" and "medium risk" offenders are much better targets for intensive intervention than low risk individuals who, it turns out, may actually be harmed by further immersion in the justice system.

Proposed interventions also must derive from reputable psychological theory and previous preliminary findings. Novel or off-the-wall treatments are unlikely to succeed. The components of an intervention (the recipe) must be clearly elaborated. "Six months of group therapy" is disqualified because of its vagueness. Even if "success" were achieved at prison X, would therapists at prison Y have the same approach to group therapy? To combat the vagueness and subjectivity problem, treatment staff must adhere to a sufficiently detailed “treatment manual." Adopters of evidence-based interventions are now routinely required to undertake extensive training. Treatment providers not only need to show expertise in the intervention details but must also maintain an acceptable level of engagement and quality control so as not to "drift" or lapse into providing a watered-down version of the treatment. 
We also must decide what "results" to look for. Suppose that an offender-client learns to recite the principles of "Thinking for a Change" (a cognitive-behavioral program)—a good first step. However, it is more critical to assess whether knowing principles is accompanied by changing target behaviors, e.g., being less impulsive and less aggressive, both during practice sessions, and in the live environment. Ultimately, we are interested in whether the intervention results in crime reduction. Collateral damage may also be an important result to track. In many cases, "treatment-as-usual" (the status quo of current conditions) has been shown to have negative, iatrogenic effects, causing actual harm. Likewise, persons enrolled in treatment programs might quickly reach a benefit ceiling, particularly if their everyday environment runs strongly counter to the thrust of the intervention.

Finally, all treatments and non-treatment interventions have associated costs. In a few jurisdictions, social and governmental costs are calculated and compared across interventions. For example, what are the costs of confining youthful offenders to an institutional program versus enrolling them in an evidence-based, multi-systemic community program? In many cases, reputable interventions show not only better outcomes but a notable return-on-investment savings. In other words, for every dollar spent in program $\mathrm{X}$, the state saves $\mathrm{Y}$ dollars. This kind of telling demonstration helps promote the original goal of contributing to informed public policy.

\section{The Future of Research in Criminal Psychology}

Psychology is well-positioned to provide a deeper understanding of crime and to promote changes in justice policy. The prison system has outgrown the country's capacity to sustain it. Just as American looked to psychology nearly two centuries ago to form the foundation for justice policy as a focus on individual people's actions that required punishment and 
rehabilitation, America may again draw from psychology while prisons are reinvented. Psychological science has shown that the contexts in which people live (critical environmental factors that promote and sustain criminal behavior) cannot be ignored. Both individual characteristics (e.g., the "big four") and harmful contexts, such as violence, substance abuse, poverty, and lack of means or ability to change one's contexts are all associated with higher risk of criminal outcomes. In contrast, interventions aimed at changing personal procriminal factors as well as those promoting positive environments have been shown to reduce the risk of criminal outcomes.

Public policy has been slow to follow these advances. More so than in many other fields, justice policies often reflect popular sentiment rather than evidence. Beliefs about "what works" are notably subjective and typically grow from entrenched personal and cultural attitudes. Consequently, proposals to implement empirically supported approaches to crime and delinquency are often met with resistance. Thus, we are called on to persistently and thoughtfully translate the results of research in a manner that promotes their adoption.

Notwithstanding the major insights from research in criminal psychology discussed above, many questions remain. Among them is the unique challenge presented by mentally disordered offenders, a group that now comprises a substantial and growing proportion of jail and prison inmates. Logically, intervention programs would address both criminal behavior as well as treatments for mental disorder. Likewise, even though drug offenders represent another huge segment of inmates, treatment outcome studies have lagged behind. How do community vs. institutional substance abuse treatments for offenders compare? Sparsely available too are studies examining the impact of correctional staff attitudes and day-to-day practices on inmate behavior. Noxious prison environments, including those where sexual assault is prevalent, can be 
an overriding factor that sets a low success ceiling to even the best available programs. Similarly, what is the potential of community-based treatment extensions? How can citizens become more attuned to and willing to consider research evidence? Future research may be able to help answer some of these questions. Insights from the science of criminal psychology may change the direction of how America deals with crime and its consequences.

Carl B. Clements and Tess M.S. Neal

See also: Criminalization Hypothesis; "Nothing Works” Debate; Research Methods in Experimental Psychology; Research Methods in Forensic Psychology; Measurements and Scales Used in Research; Meta-Analysis; Psychopathic Offenders: Current State of the Research

\section{Further Readings}

Andrews, D. A., \& Bonta, J. (2010). Rehabilitating criminal justice policy and practice. Psychology, Public Policy, and Law, 16, 39-55.

Clements, C. B., Althouse, R., Ax, R. K., Magaletta, P. R., Fagan, T. J., \& Wormith, J. S. (2007). Systemic issues and correctional outcomes: Expanding the scope of correctional psychology. Criminal Justice and Behavior, 34, 919-932

Cullen, F. T., \& Gendreau, P. (2001). From nothing works to what works: Changing professional ideology in the 21st century. The Prison Journal, 81, 313-338.

Gendreau, P., Smith, P. \& Theraiault, Y.L. (2009). Chaos theory and correctional treatment: Common sense, correctional quackery and the law of fartcatchers. Journal of Contemporary Criminal Justice, 25, 384-396. 
Haney, C., \& Zimbardo, P. (1998). The past and future of US prison policy: Twenty-five years after the Stanford Prison Experiment. American Psychologist, 53, 709-727.

Lewandowski, G.W., Ciarocco, N.J., Strohmetz, D.B. (2016). Discovering the scientist within: Research methods in psychology. New York, NY: Worth Publishers.

Magaletta, P.R., Morgan, R.D., Reitzel, L.R., \& Innes, C.A. (2007). Toward the one: Strengthening behavioral sciences research in corrections. Criminal Justice \& Behavior, 34, 933-944.

Neal, T.M.S. (under review). Forensic psychology and correctional psychology: Distinct but related subfields of psychology.

Skeem, J.L. \& Eno Louden, J. (2006). Toward evidence-based practice for probationers and parolees mandated to mental health treatment. Psychiatric Services, 57, 333-342. 